\title{
Detection of Bovine TB infection in Pre-slaughter Cattle at Selected Abattoirs in Accra, Ghana Using the BOVIGAM ${ }^{\mathrm{TM}} 2 \mathrm{G}$ Assay
}

\section{Ivy Brago Amanor ${ }^{1,2}$, Gloria Ivy Mensah ${ }^{1 *}$, Raphael Amediko ${ }^{1}$, James Edinam Futse $^{2}$ and Kennedy Kwasi Addo ${ }^{1}$}

${ }^{1}$ Department of Bacteriology, Noguchi Memorial Institute for Medical Research, University of Ghana, Legon/Accra, Ghana

${ }^{2}$ Department of Animal Science, University of Ghana, Legon/Accra, Ghana

*Corresponding Author: Gloria Ivy Mensah, Department of Bacteriology, Noguchi

Memorial Institute for Medical Research, University of Ghana, Legon/Accra, Ghana.
Received: June 18, 2020

Published: July 31, 2020

(C) All rights are reserved by Gloria Ivy

Mensah., et al.

\begin{abstract}
The Tuberculin skin test (TST) which for several years remained the only available tool for diagnosis of bovine tuberculosis (BTB) in live cattle lacks the desired sensitivity and specificity. In the past decade, the Interferon Gamma Release Assays (IGRAs) have become the preferred diagnostic tests for latent TB infection (LTBI) in humans and cattle. One of the IGRAs which is commercialized as BOVIGAMTM TB test specifically for cattle has been proven to have a higher specificity and sensitivity over the TST. BOVIGAMTM has been approved by the Office International des Epizooties (OIE) for screening of TB infection in cattle and may enable surveillance of animal health and welfare. We determined the prevalence of BTB infection in pre-slaughter cattle from three major abattoirs in Accra between May and July 2019 using the BOVIGAMTM 2G assay. Five (5 mls) blood samples (one tablespoonful) were drawn from the jugular vein of each cattle into heparin blood collection tubes for the BOVIGAMTM 2G ELISA assay which was performed according to manufacturer's instructions. A total of 125 healthy looking cattle was screened out of which 10 (8\%) were positive for BTB infection. This suggests that BOVIGAM test may provide a better indication of animal health with respect to BTB than physical examination and postmortem inspection for tuberculosis lesions.
\end{abstract}

Keywords: Bovine TB; Latent TB Infection; BOVIGAMTM 2G Test; IGRAs; Cattle; Abattoirs; Ghana

\section{Introduction}

Among the Mycobacterium tuberculosis complex (MTBC) species, cattle adapted Mycobacterium bovis is the most common cause of zoonotic TB in humans with pathology similar to $\mathrm{Myco}$ bacterium tuberculosis (MTB), which is primarily pathogenic for humans [1]. In Ghana, MTB and Mycobacterium africanum (MAF) are the most common causes of pulmonary disease in human TB [2], However a prevalence of 2(3\%) among pulmonary TB in Accra [2] and 0.8\% (15/1755) among M. tuberculosis complex (MTBC) isolated between 2012 and 2014 has been reported to be caused by $M$. bovis, indicating possible aerosol transmission between human population and cattle. In addition to inhalation, many cases of zoonotic TB occur as extra pulmonary TB acquired through consumption of unpasteurized milk and milk products or undercooked meat [3]. It is therefore critical to examine cattle for clinical signs of TB before and after slaughter to avoid infected cattle from entering the food chain. In developed countries, effective surveil- lance, and enforcement of regulations on BTB control has resulted in significant reduction of infections in cattle and thereby drastically reducing the occurrence of zoonotic TB in humans [4]. In Ghana, lack of effective surveillance systems affects accurate and timely reporting of BTB in humans and cattle [5]. The test and slaughter policy using the intradermal TST is laborious, time consuming and not often done, making ante mortem and meat inspection at abattoirs a major strategy to ensure that infected beef products do not enter the food chain. However, this strategy falls short of being effective for surveillance of BTB as it detects only cases with visible caseous lesions. An ideal screening tool for abattoir surveillance of BTB in cattle would be a test that allows detection of both infection and disease. BOVIGAM ${ }^{\mathrm{TM}}$ an ELISA based Interferon gamma release assay (IGRA) for detection of BTB infection in cattle has shown potential in several studies [6] for this purpose. The OIE approved the registration of the BOVIGAM ${ }^{\mathrm{TM}}$ TB Kit in the OIE Manual of Diagnostic Tests and Vaccines for Terrestrial Animals 2015 [7]. It is the only 
BTB, Interferon- $\gamma$ in vitro assay that is OIE-registered. The kit is validated for use in cattle, goat, buffalo (Syncerus caffer) and sheep.

BOVIGAM $^{\mathrm{TM}} 2 \mathrm{G}$ assay is an advanced form of the test which has an additional antigen, pokeweed that serves as a stimulation control for the test and quality of the blood sample, thus ensuring proper functioning of the test. The test involves the measurement of IFN- $\gamma$ produced by T-cells when stimulated with bovine Purified Protein Derivative (BvPPD) and avian Purified Protein Derivative (AvPPD) using a monoclonal antibody -based sandwich enzyme immunoassay (EIA). These IGRAs have been recommended as better tools to detect TB in eradication programmes [8]. This study used BOVIGAM ${ }^{\mathrm{TM}} 2 \mathrm{G}$ assay to screen pre-slaughter cattle at selected abattoirs in Accra for BTB.

\section{Materials and Methods}

\section{Ethical considerations}

This study protocol was reviewed and approved by the Ethics Review Committee of the Ghana Health Service, (Certified Protocol Number: GHS-ERC 019/07/18) and the Noguchi Memorial Institute for Medical Research Institutional Review Board (Certified Protocol Number: NMIMR-IRB CPN 099/17-18).

\section{Study design}

The study was cross-sectional. Three abattoirs within proximity to the University of Ghana were purposively selected to give enough time for processing of samples within 24 hours after collection (Figure 1). Permission was sought from abattoir administrators and sampling took place between May 2019 and July 2019 at early morning or dawn when the animals were usually slaughtered.

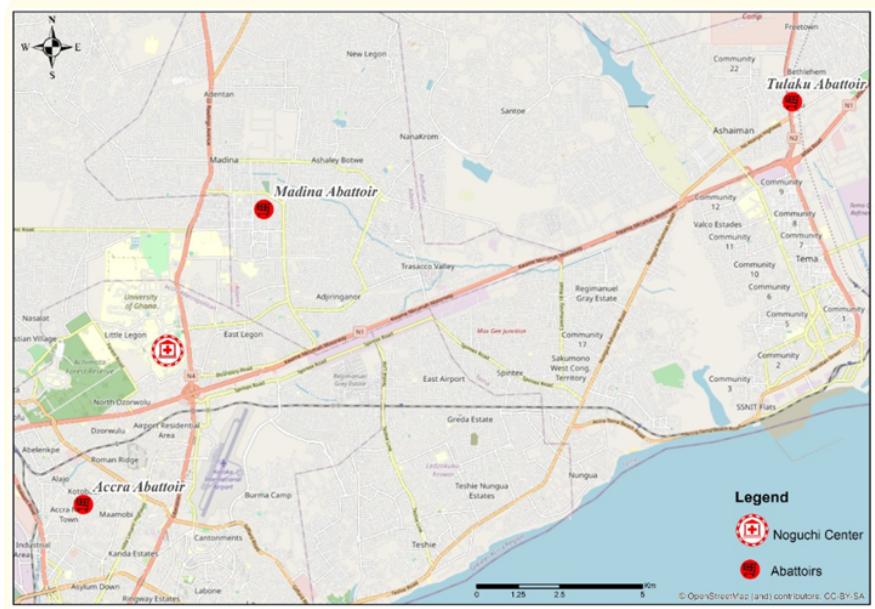

Figure 1: Location of the three abattoirs.
Sampling

Study population

All cattle brought for slaughter within the sample collection period for whom consent was given by clients who brought them to be slaughtered were eligible for inclusion.

\section{Sample collection}

Cattle were first restrained by tying their hind legs with rope. They were then gently pulled down to keep them stable so that the area around the neck to be cleaned with $70 \%$ alcohol. Using a sterile needle, five milliliters ( $5 \mathrm{ml}$ ) of blood (one tablespoonful) was drawn from the jugular vein into heparin blood collection tubes by a trained veterinary officer. All samples were transported to the laboratories of Noguchi Memorial Institute for Medical Research (NMIMR) for processing. Abattoir practices, including the extent of examination of live animals (ante mortem) and carcasses at the various abattoirs which may facilitate transmission of infections were recorded using structural forms.

\section{Detection of BTB infection using BOVIGAM ${ }^{\mathrm{TM}}$}

Testing with the BOVIGAM ${ }^{\mathrm{TM}}$ 2G TB kit (Product code: 63330 ThermoFisher Scientific, USA) involved two stages. Briefly, in the first stage, $100 \mu \mathrm{l}$ each of two mycobacterial antigens (BvPPD and AvPPD), a positive control (Pokeweed mitogen) and a negative control (phosphate buffered saline) were added to four separate wells of a micro plate. Blood samples $(250 \mu 1)$ were added to each of the four wells, mixed thoroughly by swirling and incubated overnight at $37^{\circ} \mathrm{C}$. Samples were run in duplicate. Plasma supernatant $(110 \mu \mathrm{l})$ from each well were harvested for the second stage. In the second stage, IFN- $\gamma$ in the plasma supernatants of each blood aliquot was determined using a sandwich ELISA following manufacturer's instructions. Absorbance of each well was measured within 5 minutes of terminating the reaction using a micro plate reader fitted with 450 nm filter. The absorbance value was used to calculate the results as follows:

- $\quad$ Positive $=$ OD Bovine PPD -NIL Antigen $\geq 0.100$ or OD Bovine PPD -Avian PPD $\geq 0.100$.

- $\quad$ Negative $=$ OD Bovine PPD -NIL Antigen $<0.100$ or OD Bovine PPD -Avian PPD $<0.100$

Data analysis

All data were saved in Microsoft Excel 2013 (Microsoft Corp., Washington, USA) prior to analysis. Based on the calculated absorbance values, the outcome of the BOVIGAM test was categorized as positive or negative. The proportion of positive and negative cases corresponding to different abattoirs were obtained using Fishers exact test. $P$ values less than 0.05 were considered significant. 


\section{Results}

Altogether, whole blood samples were collected from 125 cattle that had been physically examined and found suitable for slaughter by veterinary officers. Samples were collected from 3 abattoirs based at Accra ( $\mathrm{n}=51)$, Ashaiman $(\mathrm{n}=41)$ and Madina $(\mathrm{n}=33)$ in the Greater Accra Region of Ghana (Figure 1). Conditions at the three abattoirs were comparable in terms of source of water supply, waste management systems, ventilation, working floors and evisceration procedures however, only Ashaiman abattoir had a well-ventilated space where cattle were kept prior to slaughter (Table 1). Of the 125 cattle screened using the BOVIGAM ${ }^{\mathrm{TM}} 2 \mathrm{G}$ test, $10(8 \%)$ were positive for TB infection. At least, one positive case was recorded in each abattoir with the highest prevalence of $15.2 \%(5 / 33)$ being recorded at Madina abattoir (Table 2).

\section{Discussion}

Due to the difficulty in enforcing the test and slaughter policy in Ghana, physical inspection of cattle and meat inspection at abattoirs remain very important in ensuring that, meat contaminated with tuberculous mycobacteria are not released for human consumption. There are over 70 private and state owned abattoirs in Ghana [9] which can become a hub for spreading of infection and cross contamination if not properly monitored. In this regard, we observed the operating environment as well as some slaughterassociated practices at the three abattoirs involved in this study. Inadequate ventilation, overcrowding, and improper waste management among others were observed which can facilitate the spread of TB and other infections.

\begin{tabular}{|l|c|c|c|}
\hline \multicolumn{1}{|c|}{ Observed Practices } & Madina & Accra & Ashattoirs \\
\hline Ventilation & Inadequate & Inadequate & Good \\
\hline Waste Management & $\begin{array}{c}\text { Solid waste kept in bins } \\
\text { Liquid waste are connected to } \\
\text { gutters untreated }\end{array}$ & $\begin{array}{c}\text { Solid wastes kept in bins } \\
\text { Liquid waste is connected to } \\
\text { gutters untreated }\end{array}$ & $\begin{array}{c}\text { Solid wastes kept in an opened space over } \\
\text { a long period of time. Liquid waste is con- } \\
\text { nected to gutters untreated }\end{array}$ \\
\hline Source of water Supply & Water is stored in barrels & Water is stored in barrels & Water is stored in barrels \\
\hline Working floors & Rough with blood & Rough with blood & Rough with Blood \\
\hline Evisceration & Done on the floor in pool of \\
blood & $\begin{array}{c}\text { Done on the floor in pool of } \\
\text { blood }\end{array}$ & Done on the floor in pool of blood \\
\hline
\end{tabular}

Table 1: Observed practices at the three Abattoirs.

\begin{tabular}{|l|c|c|c|c|}
\hline \multirow{2}{*}{ Abattoir Location } & \multirow{2}{*}{ No of cattle tested } & \multicolumn{2}{|c|}{ Test result } & \\
\cline { 3 - 5 } & & Positive (\%) & Negative (\%) & p-value (95\% C.I) \\
\hline Madina & 33 & $5(15.2)$ & $28(84.8)$ & $0.0001(47.28 \%-81.64 \%)$ \\
\hline Accra & 51 & $4(7.8)$ & $47(92.2)$ & $0.0001(69.35 \%-91.03 \%)$ \\
\hline Ashaiman & 41 & $1(2.4)$ & $40(97.6)$ & $0.0001(80.87 \%-98.0 \%)$ \\
\hline Total & 125 & $10(8)$ & $115(92)$ & $0.0001(75.37 \%-89.09 \%)$ \\
\hline
\end{tabular}

Table 2: BOVIGAMTM $2 \mathrm{G}$ test results by Abattoir.

BOVIGAM was first used in Ghana by Addo., et al. [10] to screen for TB Infection in preslaughter cattle at five abattoirs in the Greater Accra region of Ghana. That study reported a $6.4 \%$ prevalence while the present study recorded a prevalence of $8 \%$ in three abattoirs. Earlier studies using the TST had reported a prevalence of $13.8 \%$ in the Dangme-West district $[11]$ and $2.5 \%$ on two farms in the Greater Accra of Ghana [12]. The superiority of the BOVIGAM over the TST has been well established in several studies [13]. In Switzerland, which has been officially freed of BTB since 1960, a BTB infection prevalence of $49 \%$ with BOVIGAM $^{\mathrm{TM}}$ and $14 \%$ with
TST was recorded in 2011 among cattle, clearly demonstrating the benefit of specific antigens for the diagnosis of BTB [14]. Similar studies in Cameroon [15] and Turkey [16] recorded BTB prevalence of $60 \%$ and $49.2 \%$ in pre- slaughter using the BOVIGAM ${ }^{\mathrm{TM}}$.

However, because the test does not distinguish between active and latent infection [17], lesions may not be found during examination of carcass of cattle that test positive. This could be due to either the disease being active but not advanced to a stage where pathological changes caused by the bacilli such as tissue injury and ces- 
sation have occurred, or the infection being latent $[4,18]$. In either case, the meat devoid of lesions at this stage, may be deemed free of BTB and thus suitable for human consumption even though the animal may not be healthy. This clearly shows that depending only on postmortem detection of TB lesions in animal carcasses during examination at the various abattoirs to diagnose BTB may be insufficient. It has been demonstrated that the likelihood of missing an animal with a TB lesion during abattoir inspection is 95.24\% [19]. Considering this low sensitivity of routine abattoir assessments for infected organs, the need to use more sensitive and specific screening tools such as the BOVIGAM ${ }^{\mathrm{TM}} 2 \mathrm{G}$ assay cannot be overemphasized. The major advantage of BOVIGAM ${ }^{\mathrm{TM}} 2 \mathrm{G}$ test is that, it detects infection rather than disease making it useful as a screening tool for surveillance of BTB [20]compared to molecular techniques and culture that can only be used when the bacterial loads go beyond the numbers required to detect $M$. bovis from tissue samples [21].

It is known that in some abattoirs, as well as the many unapproved slaughter facilities and homes, animals are slaughtered and dispatched for consumption without recourse to postmortem examination by veterinarians or trained meat inspectors [22]. This is on the assumption that cattle with no physical signs of illness are healthy and unlikely to be carrying any disease. The results of this study show that even healthy-looking cattle could be infected with BTB.

Due to logistical and technical challenges, we were unable to follow up on the postmortem examination of the cattle screened with the BOVIGAM ${ }^{\mathrm{TM}} 2 \mathrm{G}$ test. This would have allowed us to compare results of the postmortem examination with the BOVIGAM ${ }^{\mathrm{TM}}$ $2 \mathrm{G}$ test results. However, based on the explanation given about the implications of a positive BOVIGAM ${ }^{\mathrm{TM}}$ test, the postmortem result would not have had any significant bearing on the findings of the study.

\section{Conclusion}

The purpose of physical examination and meat inspection at abattoirs is not only to safeguard public health and food safety, but to provide an indication of animal health and welfare. For BTB, the former may be achieved, but the latter requires a test that can detect infection even at the early stages. By detecting BTB infection in eight percent (8\%) of apparently healthy cattle, BOVIGAM may be that test.

\section{Recommendation}

The BOVIGAM ${ }^{\mathrm{TM}} 2 \mathrm{G}$ assay offers an easy platform for immunosurveillance of BTB in herds of cattle and should be adopted by the
Veterinary services in Ghana for routine screening for BTB infection at abattoirs in addition to meat inspection.

\section{Acknowledgement}

Funding for this study was made possible through DELTAS Africa Initiative [Afrique One-ASPIRE /DEL-15-008] masters Fellowship grant to Ivy Brago Amanor. Afrique One-ASPIRE is funded by a consortium of donors including the African Academy of Sciences (AAS) Alliance for Accelerating Excellence in Science in Africa (AESA), the New Partnership for Africa's Development Planning and Coordinating (NEPAD) Agency, the Wellcome Trust [107753/A/15/Z] and the UK government.

The authors also appreciate the priceless efforts of Rashid, Christiana, Kwame, and Mustapha of Ashaiman, Accra and Madina abattoirs for their assistance in sample collection and Mr Seyram Kofi Loh GIS analyst at the University of Ghana for generation of the map of abattoirs.

\section{Bibliography}

1. Biet F., et al. "Zoonotic aspects of Mycobacterium bovis and Mycobacterium avium-intracellulare complex (MAC)". Veterinary Research 36.3 (2005): 411-436.

2. Addo KK., et al. "Mycobacterial species causing pulmonary tuberculosis at the korle bu teaching hospital, Accra". Ghana Medical Journal 41.2 (2007).

3. Otchere ID., et al. "Molecular epidemiology and whole genome sequencing analysis of clinical Mycobacterium bovis from Ghana". PloS One 14.3 (2019).

4. Shitaye JE., et al. "A prevalence study of bovine tuberculosis by using abattoir meat inspection and tuberculin skin testing data, histopathological and IS6110 PCR examination of tissues with tuberculous lesions in cattle in Ethiopia". Veterinarni Medicina-Praha- 51.11 (2006): 512.

5. Lopes PH., et al. "Bovine tuberculosis surveillance system evaluation, Greater-Accra region, Ghana, 2006-2011". The Pan African Medical Journal 25 (2016).

6. Helb D., et al. "Rapid detection of Mycobacterium tuberculosis and rifampin resistance by use of on-demand, near-patient technology". Journal of Clinical Microbiology 48.1 (2010): 229237. 
7. OIE. Oie approves registration of bovigam tb kit in diagnostics manual boosting global effort to manage bovine tuberculosis (2015).

8. Zumla A., et al. "WHO's 2013 global report on tuberculosis: successes, threats, and opportunities". The lancet 382.9907 (2013): 1765-1767.

9. Annan-Prah A., et al. "Slaughterhouses, animal slaughter and slaughter hygiene in Ghana". Journal of Veterinary Advances 2.4 (2012): 189-198.

10. Addo KK., et al. "Prevalence of Tuberculosis Infection in a Cohort of Cattle that enters the food chain". Mycobacterial Diseases 6.5 (2016).

11. Bonsu OA., et al. "Prevalence of tuberculosis in cattle in the Dangme-West district of Ghana, public health implications". Acta Tropica 76.1 (2000): 9-14.

12. Asante-Poku A., et al. "Prevalence of bovine tuberculosis in a dairy cattle farm and a research farm in Ghana". Onderstepoort Journal of Veterinary Research 81.2 (2014): 1-6.

13. Ryan TJ., et al. "An evaluation of the gamma interferon test for detecting bovine tuberculosis in cattle 8 to 28 days after tuberculin skin testing". Research in Veterinary Science 69.1 (2000): 57-61.

14. Schiller I., et al. "Bovine tuberculosis in Europe from the perspective of an officially tuberculosis free country: trade, surveillance and diagnostics". Veterinary Microbiology 151.1-2 (2011): 153-159.

15. Awah Ndukum J., et al. "Prevalence of bovine tuberculosis in abattoirs of the littoral and Western highland regions of Cameroon: a cause for public health concern". Veterinary Medicine International 2010 (2010).

16. Öztürk D., et al. "In vitro diagnosis of bovine tuberculosis by $\gamma$-interferon assay" (2010).

17. Frahm M., et al. "Discriminating between latent and active tuberculosis with multiple biomarker responses". Tuberculosis 91.3 (2011): 250-256.

18. Corner LA. "Post mortem diagnosis of Mycobacterium bovis infection in cattle". Veterinary Microbiology 40.1-2 (1994): 5363.
19. Teklu A., et al. "Tuberculous lesions not detected by routine abattoir inspection: the experience of the Hossana municipal abattoir, southern Ethiopia". Revue Scientifique et TechniqueOffice International Des Epizooties 23.3 (2004): 957-964.

20. Ramos DF., et al. "Diagnosis of bovine tuberculosis: review of main techniques". Brazilian journal of biology AHEAD (2015).

21. Vordermeier HM., et al. "The BOVIGAM assay as ancillary test to the tuberculin skin test". Government Veterinary Journal 16.1 (2006): 72-80.

22. Goodsell M. "Resource Guide to Direct Marketing Livestock and Poultry". (2011):32

\section{Assets from publication with us}

- Prompt Acknowledgement after receiving the article

- Thorough Double blinded peer review

- Rapid Publication

- Issue of Publication Certificate

- High visibility of your Published work

Website: www.actascientific.com/

Submit Article: www.actascientific.com/submission.php Email us: editor@actascientific.com

Contact us: +919182824667 